\title{
A preschool program for safety and injury prevention delivered by home visitors
}

\author{
B D Johnston, J Britt, L D’Ambrosio, B A Mueller, F P Rivara
}

Harborview Injury

Prevention and

Research Center and

Department of

Pediatrics, University

of Washington

B D Johnston

Harborview Injury

Prevention and

Research Center

J Britt

L D'Ambrosio

Harborview Injury

Prevention and

Research Center and

Department of

Epidemiology,

University of

Washington

B A Mueller

Harborview Injury

Prevention and

Research Center,

Department of

Pediatrics and

Department of

Epidemiology,

University of

Washington

F P Rivara

Correspondence to:

Brian D Johnston,

Harborview Injury

Prevention and Research

Center, 325 Ninth Avenue,

Box 359960, Seattle,

Washington 98104, USA

(bdj@u.washington.edu)

\begin{abstract}
Objective-To evaluate the feasibility, acceptability, and effectiveness of an injury prevention program delivered by school based home visitors to the families of low income children attending preschool enrichment programs in Washington State. Study sample-The families of children attending preschool Head Start programs in two regions were eligible. A total of 213 families $(77.8 \%$ of those eligible) from intervention sites, and 149 families $\mathbf{7 1 1 . 9 \%}$ of those eligible) from concurrent comparison sites, agreed to participate and completed the trial.

Intervention-Trained school personnel conducted home safety inspections as part of a planned home visit. Intervention families were offered educational materials as well as smoke detectors, batteries, ipecac, and age appropriate car safety restraints based on results of the home inspection.

Evaluation methods-At a repeat home visit three months later, the proportion of families with a positive change in injury prevention knowledge or behavior among those in the intervention group was compared with the proportion in the comparison group. Smoke detector presence and function were observed.

Results-Among families without a working smoke detector at baseline, the intervention was associated with an increased probability of having a working detector at follow up (relative risk (RR) 3.3, 95\% confidence interval (CI) 1.3 to 8.6). Intervention families were also more likely to report the presence of ipecac in the home (RR 4.7, 95\% CI 3.0 to 7.3) at follow up and to have obtained an age appropriate booster seat (RR 4.1, 95\% CI 1.9 to 8.8). The program was acceptable to client families and to the home visitors who conducted the intervention.

Conclusions-Among the families of low income children enrolled in preschool enrichment programs, home safety inspections and the distribution of safety supplies by school based home visitors appears to improve knowledge and behavior related to poisoning, smoke detector
\end{abstract}

installation, and car safety seat use over three months of follow up.

(Injury Prevention 2000;6:305-309)

Keywords: home visitor; preschool safety

In the Unites States, the leading causes of injury hospitalization for children between 1 and 4 years old are motor vehicle occupant injuries, falls, poisoning, and burns. ${ }^{1}$ Effective injury control interventions for families with preschool children should focus on injuries that are prevalent ${ }^{2}$ or severe ${ }^{3}$ or for which effective prevention measures are available. ${ }^{4-6}$

Pediatricians and other primary health care physicians are encouraged to engage in injury prevention counseling for families with small children. ${ }^{7}$ Unfortunately, counseling in clinical settings alone has seldom been demonstrated to reduce injury rates. ${ }^{89}$ For most children the number and intensity of contacts with the medical care system decreases greatly after the second birthday and-when surveyedrelatively few families recall receiving injury prevention advice from a physician. ${ }^{10}$ Programs based outside the medical setting are needed to improve the delivery of injury prevention services to preschool aged children. Previously evaluated interventions have been delivered at preschools, with ${ }^{11}$ and without ${ }^{12}$ a home based component, and as community education campaigns. ${ }^{13} 14$ These services have been provided by public health nurses ${ }^{15}$ and by home visitors. ${ }^{16-18}$

In the United States, Head Start is a government funded preschool enrichment program designed to provide services to children at risk for poor educational outcomes because of socioeconomic deprivation. ${ }^{19}$ Washington State's Early Childhood Education and Assistance Program (ECEAP) is a state funded analogue of the federal program. Eligibility criteria, staffing, and services offered are identical in both programs. Head Start and ECEAP both include scheduled home visits by school personnel as an enhancement to the daily curriculum. These home visits - by family service case workers - are designed to reinforce program curricula, to assess the home environment, to support parental follow through on identified child health and learning goals, and 
to facilitate family access to community resources.

We describe the results of a pilot program that targeted risk factors for injury to preschool aged children through a home safety assessment and home based intervention provided by Head Start case workers. Our goals were to assess the feasibility and acceptability of a home safety inspection and intervention delivered by Head Start staff, and to measure the effect of these home visits on injury related knowledge and behavior of parents of preschool aged children.

\section{Methods}

We conducted a home based injury prevention intervention that included a concurrent comparison group. Study participants were the families of children in a defined geographic area who were 4 or 5 years old and enrolled in Head Start or ECEAP between January and June 1998.

During the study period there were nine Head Start/ECEAP centers operating in Washington State's Mason and Thurston Counties and the adjacent Aberdeen region. All children enrolled at these centers were eligible to participate in the study. Randomization at the level of the individual or at the level of the center was not considered feasible by local program staff. We thus constructed two groups of Head Start/ECEAP centers based on size, geographic proximity, and independence of program staff. Six centers, with 274 eligible families, were assigned to one group, and the remaining three centers, with 207 eligible families, to a second group. After the two groups were constructed a coin was tossed to determine which would receive the intervention.

Head Start and ECEAP employ case workers (educational paraprofessionals without specialized medical training) who provide home visits as part of the preschool education and family support curriculum. Head Start/ ECEAP programs offer home visits on varying schedules, but all sites participating in this trial conducted home visits at least once a month. Nineteen case workers were trained to administer home safety questionnaires, to inspect and test smoke detectors, and to deliver a standardized home safety intervention. Inspections and interventions were conducted during regularly scheduled monthly or bimonthly home visits.

The case worker approached families about participation during a scheduled home visit. Case workers administered a baseline home safety assessment to all participant families. Information collected included: (1) the number, location, and operational status of smoke detectors in the home; (2) the poisoning prevention knowledge of the respondent; (3) the presence of ipecac; (4) the presence of hazardous chemicals and medications; and (5) and the presence and self reported use of age appropriate child safety restraints in cars owned by the family. Case workers tested smoke detectors in the home by manually depressing the test button as well as by using "canned smoke".

Families in the intervention group were then given safety related information and supplies as needed, according to an intervention "menu" designed to address all safety concerns identified by during the standardized assessment. The intervention could include provision of a new smoke detector or smoke detector batteries, syrup of ipecac and written material regarding its appropriate use, or a free booster seat if the family vehicle was equipped with rear seat lap-shoulder restraints. Families in the comparison group only received written information encouraging them to install smoke detectors or to replace batteries if needed, to obtain ipecac, and to obtain and properly use a booster seat. To insure that all families ultimately received a safety benefit from the project, comparison group families were provided with ipecac, booster seats, and smoke detector supplies after the follow up surveys were completed, although these families were not informed of this at baseline.

Outcome data were obtained three months after enrollment. The same case worker visited enrolled families and repeated the home safety assessment. Direct inspection and testing of smoke detectors was again used to ascertain functional status. The results of the follow up survey were used to create a change indicator for each family with respect to targeted injury prevention facts or behaviors. A positive change in behavior or knowledge was recorded when, for example, a family who reported the lack of a safety device at baseline subsequently reported or demonstrated the presence of that device at follow up. A neutral outcome was noted when there was no change in knowledge or behavior at follow up and a negative change was recorded when, for example, a safety device was present at baseline but lacking at follow up. The occurrence of knowledge or behavior change according to group assignment was compared and the relative risk of positive change was estimated. Statistical calculations of the Mantel-Haenszel risk estimates, with $95 \%$ confidence intervals (Taylor series), were performed using EPI-Info.

To identify potential barriers to program implementation, case workers were sent a brief semistructured mail questionnaire at the conclusion of the intervention period. They were asked about the time involved in the conduct of these home safety related visits, the feasibility of addressing several safety issues during a single home visit, and about their positive or negative experiences associated with the delivery of the intervention.

This study was reviewed and approved by the Human Subjects Committee at the University of Washington.

\section{Results}

Of 274 eligible families in the intervention sites, $258(94.2 \%)$ were enrolled in the trial whereas, in the comparison sites, 160 of 207 eligible families $(77.3 \%)$ chose to participate. Altogether 213 families in the intervention 
Table 1 Baseline characteristics of eligible children and families

\begin{tabular}{lll}
\hline & $\begin{array}{l}\text { Eligible families at } \\
\text { intervention centers (\%) } \\
(n=274)\end{array}$ & $\begin{array}{l}\text { Eligible families at } \\
\text { comparison centers (\%) } \\
(n=207)\end{array}$ \\
Child/family characteristic & & \\
Child's gender & 52.5 & 52.9 \\
$\quad$ Male & 47.5 & 47.1 \\
$\quad$ Female & 69.4 & 70.0 \\
Child's race/ethnicity & 7.4 & 2.3 \\
$\quad$ Caucasian & 10.6 & 13.8 \\
African American & 0.8 & 2.7 \\
Hispanic & 4.6 & 10.7 \\
Asian/Pacific Islander & 1.3 & 0.3 \\
Native American/Alaskan Native & & \\
$\quad$ Other & 86.9 & 89.3 \\
Child's primary language & 13.1 & 10.6 \\
English & & \\
$\quad$ Non-English & 35.2 & 48.2 \\
Child resides with & 63.8 & 48.6 \\
Both parents & 0.9 & 3.2 \\
Single parent & 45.0 & 40.2 \\
$\quad$ Foster family & 11.1 & 20.1 \\
At least one parent employed & $\$ 9442$ & $\$ 8745$ \\
Child has educational disability & & \\
Median household income & &
\end{tabular}

Table 2 Baseline prevalence of injury related knowledge and behavior among enrolled families in intervention and comparison groups

\begin{tabular}{lll}
\hline & $\begin{array}{l}\text { Families receiving } \\
\text { intervention }(n=213):\end{array}$ & $\begin{array}{l}\text { Families in comparison } \\
\text { Nooup }(n=149): \\
\text { No/total responses (\%) }\end{array}$ \\
\hline $\begin{array}{l}\text { Safety characteristic } \\
\begin{array}{l}\text { At least one working smokes detector } \\
\text { Poisoning prevention }\end{array}\end{array}$ & $198 / 211(93.8)$ & $133 / 143(92.9)$ \\
$\quad \begin{array}{l}\text { Poisons within reach of child } \\
\text { Unused medications in home }\end{array}$ & $84 / 210(40.0)$ & $33 / 143(23.0)$ \\
$\quad \begin{array}{l}\text { Knowledge of poison control line } \\
\text { Understand use of ipecac }\end{array}$ & $195 / 210(11.4)$ & $26 / 143(18.1)$ \\
$\quad$ Ipecac available in home & $132 / 208(65.4)$ & $132 / 143(92.3)$ \\
Child safety restraints & $62 / 206(30.1)$ & $84 / 143(58.8)$ \\
$\quad$ Child has safety seat & $55 / 142(28.2)$ \\
$\quad \begin{array}{l}\text { Family instructed on car seat use } \\
\text { Lap-shoulder belts in rear seat }\end{array}$ & $76 / 126(60.3)$ & $33 / 140(23.6)$ \\
$\quad$ Child is "always" buckled up & $78 / 182(42.9)$ & $41 / 62(65.1)$ \\
\hline
\end{tabular}

Table 3 Relative proportions of families reporting positive knowledge or behavior change over three month follow up period

\begin{tabular}{|c|c|c|c|}
\hline & $\begin{array}{l}\text { Intervention } \\
\text { group: } \\
\text { No/total No (\%) }\end{array}$ & $\begin{array}{l}\text { Comparison } \\
\text { group: } \\
\text { No/total No (\%) }\end{array}$ & $R R(95 \% C I)$ \\
\hline \multicolumn{4}{|l|}{ Smoke detectors } \\
\hline Obtained first working detector ${ }^{\star}$ & $13 / 13(100.0)$ & $3 / 10(30.0)$ & $3.3(1.3$ to 8.6$)$ \\
\hline Added at least one working detector & $58 / 203(28.6)$ & $20 / 137(14.6)$ & $2.0(1.2$ to 3.1$)$ \\
\hline \multicolumn{4}{|l|}{ Poisoning prevention } \\
\hline Removed poisons from home & $61 / 202(30.2)$ & $20 / 135(14.7)$ & $2.1(1.3$ to 3.2$)$ \\
\hline Disposed of unused medicine & $18 / 202(8.9)$ & $16 / 134(11.9)$ & $0.8(0.4$ to 1.4$)$ \\
\hline Learned about poisoning resources & $15 / 203(7.4)$ & $11 / 134(8.2)$ & $0.9(0.4$ to 1.9$)$ \\
\hline Learned about use of ipecac & $68 / 200(34.0)$ & $27 / 137(19.7)$ & $1.7(1.2$ to 2.5$)$ \\
\hline Obtained ipecac for the home & $124 / 198(62.6)$ & $18 / 134(13.4)$ & 4.7 (3.0 to 7.3$)$ \\
\hline \multicolumn{4}{|l|}{ Child safety restraints } \\
\hline Obtained child safety seat & $42 / 195(21.5)$ & $7 / 132(5.3)$ & $4.1(1.9$ to 8.8$)$ \\
\hline Learned about car seat use† & $22 / 66(33.3)$ & $3 / 34(8.8)$ & $3.8(1.2$ to 11.7$)$ \\
\hline "Always" buckle up child & $26 / 189(13.8)$ & $10 / 132(7.6)$ & $1.8(0.9$ to 3.7$)$ \\
\hline
\end{tabular}

*Among those with no working detector at baseline.

†Among those reporting no instruction at baseline.

group $(82.5 \%)$ and 149 of those in the comparison group (93.1\%) completed both a baseline and follow up assessment. Analysis is restricted to those families who completed both assessments.

The demographic characteristics of families with children attending intervention and comparison centers, in aggregate, are shown in table 1 . In response to concerns about the confidentiality of information, demographic information about individual children or families in the enrolled sample and about nonrespondents is not available. The intervention and comparison groups demonstrated similar levels of knowledge and similar behavioral characteristics at baseline, except that families in the intervention group were more likely to report unsafe storage of poisonous substances (table 2).

Table 3 shows the proportion of families in the intervention and comparison groups who reported positive changes in knowledge or safety related behavior at follow up. Beneficial intervention effects were seen in all targeted safety domains.

\section{SMOKE DETECTORS}

Families in the intervention group who did not have any working smoke detector at baseline were three times more likely to have one at follow up than were comparison families who did not have a smoke detector at baseline (relative risk $(\mathrm{RR})=3.3,95 \%$ confidence interval $(\mathrm{CI})$ $=1.3$ to 8.6). Intervention families with at least one working smoke detector at baseline were twice as likely to have increased the number of working smoke detectors at follow up than were families in the comparison group $(\mathrm{RR}=$ $2.0,95 \% \mathrm{CI}=1.2$ to 3.1 ).

\section{POISONING PREVENTION}

Among those families who reported poisonous substances in their home at the baseline, those in the intervention group were twice as likely to have removed these substances at follow up than were families in the comparison group $(\mathrm{RR}=2.1,95 \% \mathrm{CI}=1.3$ to 3.2$)$. No difference in the level of positive change was seen between the groups, however, with respect to disposal of unused medications $(\mathrm{RR}=0.8,95 \% \mathrm{CI}=0.4$ to 1.4 ), nor were any differences noted in the proportion of families reporting familiarity with sources of help for poisoning or ingestion.

Only $20 \%$ of comparison families reported an increase in knowledge about the use of ipecac compared with $34 \%$ of intervention families ( $R R=1.7,95 \%$ CI 1.2 to 2.5$)$. Intervention families were also more than four times as likely to report the presence of ipecac in the home at follow up ( $\mathrm{RR}=4.7,95 \% \mathrm{CI} 3.0$ to 7.3).

\section{CHILD SAFETY RESTRAINTS}

The proportion of families with age appropriate booster seats was similar between groups at baseline but, at follow up, $22 \%$ and $5 \%$ of the intervention and comparison groups, respectively, reported the presence of a new, age appropriate restraint $(\mathrm{RR}=4.1,95 \% \mathrm{CI}=1.9$ to 8.8 ). Among those who reported no previous instruction in the use of car safety seats at baseline, $33 \%$ of the intervention group and $9 \%$ of the comparison group reported having received such instruction at follow up $(R R=$ $3.8,95 \% \mathrm{CI}=1.2$ to 11.7$)$. Families who received the intervention were almost twice as likely to report a positive behavior change with respect to "always" having the index child restrained in the car $(\mathrm{RR}=1.8,95 \% \mathrm{CI}=0.9$ to 3.7 )

CONDUCT OF INTERVENTIONS

Families in both groups were receptive to this home safety assessment conducted by a non-medical case worker previously known to 


\section{Key points}

- Preschool based case workers, without specialized health training, can deliver an injury prevention intervention in the homes of enrolled children.

- A home safety inspection, coupled with delivery of needed safety supplies, improved injury related knowledge and behavior for at least three months.

- The use of educational case workers in an injury control program was acceptable to client families and to the case workers.

- The ability of programs of this nature to produce long term changes or to address injury hazards other than those studied, was not assessed.

the family. As judged by the case workers, $89.1 \%$ of families in the intervention group and $88.9 \%$ of families in the comparison group were "very" receptive to the baseline survey and inspection. These proportions did not change at follow up.

Case workers reported that conducting the home safety assessment added 10 to 30 minutes to a scheduled home visit. Some of the case workers expressed reservations about entering and inspecting "private" areas of the home to test smoke detectors. Others were concerned about their role in "dispensing medications" like ipecac. However, all case workers agreed that the provision of smoke detectors, batteries, and child safety seats was professionally rewarding and of potential benefit to client families.

\section{Discussion}

These results suggest that, among families with children enrolled in a preschool enrichment program, an injury control intervention conducted by family service case workers improved injury related knowledge and behavior related to poisoning, smoke detector installation and car safety seat use, over three months of follow up. In this intervention, active provision of child safety supplies was used to augment the home inspection and the distribution of educational materials. The number of working smoke detectors was significantly increased among intervention families as compared with families receiving only instruction. Similar increases in poisoning prevention knowledge and possession of ipecac were noted and the proportion of families who obtained or learned about appropriate car safety restraint devices was greater in the intervention group.

The injury related behaviors targeted reflect significant causes of injury morbidity in preschool aged children. Most participant families had at least one working smoke detector at baseline and the majority used some form of car safety restraint. Unfortunately, most participant families reported that their automobiles did not have rear seat lap-shoulder belts suitable for use with a safety positioning booster seat, a fact that limited the potential gains in safety seat usage attributable to the program. Greater opportunities for change in poisoning prevention were noted, as most families did not possess ipecac. These patterns of injury related knowledge and behavior are consistent with those reported in previous studies of Head Start families. ${ }^{20}$

Our study used a concurrent comparison group, but randomization at the level of the individual or center was not employed. Unfortunately, we did not have demographic information to allow us to compare the characteristics of families enrolled in the intervention and comparison groups. Data about individual children were not available from the participating centers. Even if these data were present, differences in the baseline distribution of child characteristics (and the potential confounding effect of these differences) would be difficult to interpret because families, not individual children, were the targets of the intervention.

Nevertheless, we believe that the key benefits seen in the intervention group are unlikely to have resulted from systematic differences between the groups at baseline. Instead, increases in the number of working smoke detectors, the number of households possessing ipecac, and the number of families using age appropriate car safety restraints are most likely due to the active provision, installation, and demonstration of these safety supplies by the case workers.

This study was also limited insofar as it relied upon self reported data regarding certain key behavioral outcomes. A direct assessment of ipecac presence and the use of appropriate car safety seats would have been ideal but this was not possible given the competing demands of the curriculum and objectives of the case workers. Our follow up at three months demonstrated that the beneficial effects of this intervention were immediately detectable, although a longer follow up would be required to test the durability of these changes. And, while not a defined outcome in this study, it would also be desirable to assess actual injury rates.

Although successful injury prevention activities have been conducted in the preschool age group ${ }^{11}$ this study was unique insofar as it employed Head Start family service case workers, who had on-going relationships with participant families. The intervention was delivered at the home by case workers during a scheduled visit, without the time and expense of an additional trip to conduct a safety assessment. Although previous work suggested that home visitors might find the time commitment of conducting home safety checks onerous, both the home visitors and their clients reported these visits to be acceptable and useful, requiring little time and expanding the range of services offered to families. The case workers saw the direct provision of safety supplies as especially beneficial, perhaps reflecting the substantial financial barriers that prevent many low income families from acquiring recommended home safety devices. ${ }^{21}$ Although the intervention was acceptable to the Head Start case workers who participated in this study, it should be noted that these workers make monthly visits to client families. Pro- 
grams that make fewer routine home visits might find the task of conducting such an intervention, when added to the standard curriculum, to be more burdensome.

Families in this study were all low income, as defined by their eligibility for Head Start/ ECEAP services. Poor children are believed to be at increased risk of serious injury. ${ }^{22} 23$ Reasons for this might include the lack of availability of safety equipment, the presence of a more hazardous environment, or both. We have shown that injury prevention information and supplies can be delivered to such families for the relatively modest marginal cost of the additional time spent at the home by the case worker. This intervention appears to be one way to reduce the increased injury risk of poor children while employing existing resources in a novel health promotion program. In this respect, the Head Start program, with both school and home based family contacts, is especially well suited as a locus of injury control.

Future avenues for research and program expansion involve the addition of components to address other safety concerns identified in previous Head Start surveys: these include safe storage of firearms and techniques to reduce the risk of falls, scald burns, drowning, and choking. ${ }^{20}$ In addition, long term follow up of knowledge and behavior change would be desirable, as would an assessment of specific injury rates.

\section{Implications for prevention}

Preschool aged children in low income families are believed to be at increased risk for unintentional injury. In the United States many such children are enrolled in preschool enrichment programs and may be receiving routine home visits from program staff. Our trial suggests that these educational case workers can be trained to conduct home safety inspections and to provide an injury control intervention as a component of their home visits. The additional time and effort required is modest when compared to other interventions designed to reach this segment of the population, such as mass media campaigns or home visiting by public health personnel specifically to promote injury control. This trial did not, however, directly address the need for active provision of safety supplies, a program component that could represent a major element of the cost.

The actual content of the injury prevention intervention delivered by educational case workers should reflect the local epidemiology of injuries among preschool aged children. Additional studies will be required to assess the utility of these interventions when applied to injury problems not related to smoke detectors, poisoning prevention, and the use of car safety seats.

This project was funded by the Washington State Department of Health, Injury Prevention Program.

The authors would like to acknowledge the assistance of Ilene Silver at the Washington State Department of Health, Injury Silver at the Washington State Department of Health, Injury
Prevention Program, Karin Calhoun of the Mason-Thurston Prevention Program, Karin Calhoun of the Mason-Thurston
Head Start/ECEAP Program and Nancy Liedtke from the Head Start/ECEAP Program and Nancy Liedtke from
Aberdeen School District Head Start/ECEAP Program.

1 Grossman D. The epidemiology and history of child and adolescent injury prevention. The Future of Children $2000 ; 10$ (2) (in press).

2 Scheidt PC, Harel Y, Trumble AC, et al. The epidemiology of nonfatal injuries among US children and youth. Am 7 Public Health 1995;85:932-8.

3 Cohen LR, Runyan CW, Downs SM, et al. Pediatric injury Cohen LR, Runyan CW, Downs SM, et al. Pediatric injury
prevention counseling priorities. Pediatrics 1997;99:704prevent 10.

4 Dowswell T, Towner EM, Simpson G, et al. Preventing childhood unintentional injuries - what works? A literature review. Inj Prev 1996;2:140-9.

5 Bond GR. Home use of syrup of ipecac is associated with a reduction in pediatric emergency department visits. Ann Emerg Med 1995;25:338-43.

6 Runyan CW, Bangdiwala SI, Linzer MA, et al. Risk factors for fatal residential fires. N Engl f Med 1992;327:859-63.

7 American Academy of Pediatrics Committee on Injury and Poison Prevention. Office-based counseling for injury prevention. Pediatrics 1994;94(4 pt 1):566-7.

8 Clamp M, Kendrick D. A randomised controlled trial of general practitioner safety advice for families with children ueneral practitioner safety advice for fami 5 years. $B M \mathcal{F} 1998 ; 316: 1576-9$.

9 Bass JL, Christoffel KK, Widome M, et al. Childhood injury prevention counseling in primary care settings: a critical prevention counseling in primary care settings: a
review of the literature. Pediatrics 1993;92:544-50.

10 Quinlan KP, Sacks JJ, Kresnow M. Exposure to and compliance with pediatric injury prevention counseling-United States, 1994. Pediatrics 1998;102(5):e55 (electronic pages).

11 Britt J, Silver I, Rivara FP. Bicycle helmet promotion among low income preschool children. Inj Prev 1998;4:280-3. 12 Hendricks CM, Echols D, Nelson GD. The impact of a pre-
school health curriculum on children's health knowledge. $\mathcal{F}$ Sch Health 1989;59:389-92.

13 Colver AF, Hutchinson PJ, Judson EC. Promoting children's home safety. BMf 1982;285:1177-80.

14 Guyer B, Gallagher SS, Chang BH, et al. Prevention of childhood injuries: evaluation of the Statewide Childhood Injury Prevention Program (SCIPP). Am ₹ Public Health 1989;79:1521-7.

15 Ulione MS, Donovan E. Nursing in project Head Start: improving health. Issues in Comprehensive Pediatric Nursing 996;19:227-37.

16 Hardy JB, Streett R. Family support and parenting education in the home: an effective extension of clinicbased preventive health care services for poor children. $\mathcal{F}$ Pediatr 1989;115:927-31.

17 Paul C, Sanson-Fisher R, Redman S, et al. Preventing accidental injury to young children in the home using volunteers. Health Promotion International 1994;9:214-49.

18 Kitzman H, Olds DL, Henderson CR Jr, et al. Effect of prenatal and infancy home visitation by nurses on pregnancy outcomes, childhood injuries, and repeated childbearing. A randomized controlled trial. $\mathfrak{F A M A}$ 1997;278:644-52.

19 Head Start Home Page, http://www2.acf.dhhs.gov/ programs/hsb/index.html. Administration for Children and Families, US Department of Health and Human Sevices, 1999.

20 Hendricks CM, Reichert A. Parents' self-reported behaviors related to health and safety of very young children. $\mathcal{F}$ Sch Health 1996;66:247-51.

21 Paul CL, Redman S, Evans D. The cost and availability of devices for preventing childhood injuries. $\mathcal{F}$ Paediatr Child Health 1992;28:22-6.

22 Durkin MS, Davidson LL, Kuhn L, et al. Low-income neighborhoods and the risk of severe pediatric injury: a small-area analysis in northern Manhattan. Am $\mathcal{f}$ Public Health 1994;84:587-92.

23 Nersesian WS, Petit MR, Shaper R, et al. Childhood death and poverty: a study of all childhood deaths in Maine, 1976 to 1980 . Pediatrics $1985 ; 75: 41-50$. 